\title{
Designing and Validating Tests for Measuring the Performance Level of Some Basic Skills for Table Tennis Juniors
}

\author{
Sherif Fathy Saleh ${ }^{1}$, Mohamed El-Sayed Abd El-Gawad ${ }^{2}$ \\ ${ }^{1}$ Professor of Racquet Sports at the Department of Team and Racquet Sports, Faulty of Physical Education, Tanta University, \\ Egypt \\ ${ }^{2}$ Lecturer at the Department of Team and Racquet Sports, Faulty of Physical Education, Tanta University, Egypt
}

\begin{abstract}
:
Aim: To design a set of specific tests, establish standardized levels and establish benchmarks for measuring performance endurance of some basic skills for junior table tennis players using ball canon. Methods: The researchers used descriptive (survey) approach. Research community included all junior table tennis players who were registered in the Egyptian Table Tennis Federation during 2016-2017 (n=352). Participants $(n=112)$ were distributed to pilot sample group of (16) players (14.3\%) and main sample group of (96) players (85.7\%). Results: The researchers designed a set of validated tests for measuring performance endurance of some basic skills for table tennis junior players using the ball canon. The set of tests enjoy high validity and reliability and this indicates it objectivity. The set of tests diagnose weaknesses and strengths of junior table tennis players less than 18 years concerning performance endurance of some basic skills on various places of the table. The set of tests cover the most frequently used basic skills in various game situations. Criteria of tests (velocity - spin - direction - place) can be used in measuring all individual and complex basic skills according to various game situations. The set of tests help categorizing players and improving their abilities according to fast improvements in table tennis. The researchers established the standard levels of performance endurance tests for junior table tennis players less than 18 years. The researchers established the benchmarks of performance endurance tests for junior table tennis players less than 18 years. The researchers established the levels of performance endurance for junior table tennis players less than 18 years using these tests.
\end{abstract}

Keywords: Validated Tests - Ball Canon - Performance Endurance - Basic Skills - Table Tennis

\section{Introduction:}

$\mathrm{S}$ ports excellence is a modern aspects of nation's development as increased achievements in sport refer to scientific development of nations and levels of using science in improving sport. Evaluation methods in general, and especially tests and measurements, are basic pillars for making physical education and sport a science and profession.

Farahat, L. (2012) indicated that recent years witnessed major improvements in objective methods of measurement and evaluation and most problems of the sports field can be solved using specialized measurements and tests that are scientifically validated. This means that coaches should have accurate and validated objective measurements that can be used to identify effort exerted during training process and the extent to which training programs achieve its desired objectives to reach elite sports levels (Farahat, L. 2012: 4).
Abd El-Fattah, A. (2012) indicated that the concept of endurance is not limited to performance for a prolonged period of time. Instead, as a general concept endurance is the ability to overcome all types of fatigue. Specific endurance is the athlete's ability to overcome fatigue resulting from specific loads of the specific sports activity during training and competition. He thinks that external aspects of specific endurance can be summarized in the athlete's ability to maintain performance level during competition. It is manifested in: maintaining performance speed - increasing the number of effective attack overcoming gradual increase in performance intensity maintaining a high level of technical performance during competition (Abd El-Fattah, A. 2012: 196).

Abd El-Zaher, M. (2014) indicated that specific endurance is a complex quality as it is related to directing elements of competitive success in the specific sport including style of performance, technical and tactical economics, specific speed endurance and high levels of mental qualities 
required for the specific activity (Abd El-Zaher, M. 2014: 122).

The researchers think that specific endurance is the athlete's ability to maintain high intensity physical and technical abilities for a relatively long period of time. Therefore, coaches should consider linking specific endurance exercises to specific performance according to temporal and dynamic tempo. Competitive and specific exercises should take a longer period of time during training units.

Kondric, M. et al (2013) and Ghareeb, M. (2013) indicated that table tennis has evolved greatly during recent years due to investing and using modern technologies from various scientific fields. This is clear in ball velocity as it reached $180 \mathrm{~km} / \mathrm{h}$ and major improvements on racquet leather coatings. These applications can be used in improving training programs to achieve elite levels as it increases the physical performance level of the player which in turn is reflected positively on his/her technical and tactical performance levels in international competitions (Kondric, M. et al 2013: 362) (Ghareeb, M. 2013)

ITTF laws (2016) indicated that match runs should be an odd number, according to the competitive level and method of organization in a given championship. Therefore, several organization committees of international championships modified the number of runs to be (7) for the 16-round, instead of (5). This reflects the player's physical, physiological and technical level of control over the match $(20,29)$

Abd El-Gawad, M. (2014) indicated that a table tennis player should master all basic skills as they are all equal in importance. Mastering these skills requires continuous practice in every training unit for each skill individually and then to practice them in the form of complex tactical patterns similar to competitive situations considering that training duration should be proportionate to match duration so that the player can choose the best skills suitable for each game situation from the beginning to the end (Abd El-Gawad, M. 2014: 10).

The researchers reviewed the available studies related to designing tests for basic table tennis skills (Pushpendra Purashwani et al 2010: 89) (Saleh, S. 2011: 114) (Kastikadelis, M. et al 2014).

This review of literature revealed that most of these studies designed tests for speed or accuracy of basic skills, other aspects of physical fitness or counterattack. None of these studies discussed performance endurance or using double-head ball canon that can control ball velocity, direction, place or progression through the control unit of the device. This led the researchers to try to design validated tests for basic skills performance endurance for junior players less than 18 years.

According to the first researcher's experience as a national and international coach, chairman of the coaches' committee and secretary of the scientific committee of the Egyptian Table Tennis Federation, and according to the second researcher's experience as a former table tennis player and champion and coach in several sports clubs, in addition to review of related literature, they noticed that the training process requires objective evaluation for achieving its general objectives. They also noticed that performance endurance for basic skills requires validated objective evaluation the coach can rely on as most players seem weak at the end of each round especially round five and seven when the match reaches its peak duration when regular methods of scoring points are transformed into alternative methods when the mean time of match reaches 30 minutes. Coaches usually use individual estimations which are considered non-objective methods of evaluation. This led the researchers to design tests for evaluating performance endurance of some table tennis basic skills through physical-technical evaluation and establishing standard levels reflecting the real level of the player so that players are encouraged to perform better and try to reach elite levels.

Previous studies indicated that there are no unified standards for evaluating the performance level and progressive development of performance endurance abilities for table tennis players during training or competitions through objective standardized levels that turn raw points into standard points for each age group (Pradas, F. et al 2010: 177) (Kasai, J. et al 2010: 14) (Katsikadelis, M. et al 2010: 51) (Pushpendra Purashwani et al 2010: 89) (Katsikadelis, M. et al 2014).

This research is a try towards objective evaluation as designing training programs is linked to providing evaluation tools that enable us to monitor the effects of the training program and recognize improvements in results through comparison of pre- and post-tests. Therefore, this research is required for the following reasons:

1- It is applied on a critical age group as player transfer from cadets to juniors and then to men championships and this age group controls the player's attitudes towards continuing his/her career or withdrawal.

2- Previous studies concerning this topic are insufficient. 
3- The current research tries to identify the performance endurance level of juniors less than 18 years and their mastery of complex skills in game-like situations

4- It is a try to establish objective versus subjective tests.

\section{Aims:}

The current research aims to:

1- Design a set of specific tests for measuring performance endurance of some basic skills for junior table tennis players (less than 18 years) using ball canon

2- Establishing standardized levels for performance endurance tests of some basic skills for junior table tennis players (less than 18 years) using ball canon
3- Establishing benchmarks for performance endurance tests of some basic skills for junior table tennis players (less than 18 years) using ball canon

\section{Methods:}

\section{Approach:}

The researchers used descriptive (survey) approach.

\section{Participants:}

Research community included all junior table tennis players who were registered in the Egyptian Table Tennis Federation during 2016-2017 $(n=352)$. Participants were purposefully chosen from players who participated at the open Republic Championship - RAS ELBAR 2016. Table (1) shows description of participants.

Table (1)

Description of participants

\begin{tabular}{|c|c|c|}
\hline Sample & Number & Percentage \\
\hline Pilot sample & 16 & $14.3 \%$ \\
\hline Main sample & 96 & $85.7 \%$ \\
\hline Sum & 112 & $100 \%$ \\
\hline
\end{tabular}

Table (1) shows that total number of participants was (112) distributed to pilot sample group of (16) players (14.3\%) and main sample group of (96) players (85.7\%). Homogeneity of participants is shown in table (2).

Table (2)

Homogeneity of participants on main research variables $(n=96)$

\begin{tabular}{|c|c|c|c|c|c|c|c|}
\hline & \multicolumn{2}{|c|}{ Variable } & Measurement & Mean & SD & Median & Squewness \\
\hline \multirow{3}{*}{1} & \multirow{3}{*}{ Growth factors } & Age & Year & 17.0468 & 0.5438 & 16.60 & 0.160 \\
\hline & & Height & $\mathrm{Cm}$ & 171.415 & 1.448 & 170.2 & -0.149 \\
\hline & & Weight & $\mathrm{Kg}$ & 64.806 & 1.614 & 65.00 & 0.315 \\
\hline 2 & \multicolumn{2}{|c|}{ Experience } & Year & 6.135 & 0.3550 & 5.700 & 0.864 \\
\hline
\end{tabular}

Table (2) indicated that squewness values ranged from 0.864 to 0.149 (between \pm 3 ). This indicates data normality and participants' homogeneity.

\section{Planning for main experiment:}

Participants were divided into two groups (48 participants each). Group 1 was also divided into two sub-groups (24 participants each). Table (3) shows participants division on groups.

Table (3)

Division of participants into groups

\begin{tabular}{|c|c|c|}
\hline Groups & Number & Purpose \\
\hline \multirow{2}{*}{ Group 1 } & $\mathrm{N} 1=24$ & Assuring suitability of tests (easiness - difficulty) to participants \\
\cline { 2 - 3 } & $\mathrm{N} 2=24$ & Calculating validity of tests \\
\hline Group 2 & $\mathrm{N} 3=48$ & Calculating reliability of tests \\
\hline Sum & $\mathrm{N}=96$ & Preparing benchmark tables of tests \\
\hline
\end{tabular}

Table (3) showed division of participants $(n=96)$ into three groups for preparing benchmark tables of recommended tests. For homogeneity of participants of the three groups, the researchers calculated homogeneity for each group.

Table (4)

Homogeneity of the three groups on basic research variables

\begin{tabular}{|l|l|l|l|l|l|l} 
Variables & Measurement & Groups & Mean & SD & Median & Squewness \\
\hline
\end{tabular}




\begin{tabular}{|c|c|c|c|c|c|c|c|c|}
\hline & \multicolumn{2}{|c|}{ Variables } & Measurement & Groups & Mean & SD & Median & Squewness \\
\hline \multirow{9}{*}{1} & \multirow{9}{*}{$\begin{array}{l}\text { Growth } \\
\text { factors }\end{array}$} & \multirow{3}{*}{ Age } & \multirow{3}{*}{ Year } & $\mathrm{N} 1=24$ & 17.0214 & 0.5630 & 16.780 & 0.218 \\
\hline & & & & $\mathrm{N} 2=24$ & 17.0536 & 0.5384 & 16.860 & 0.136 \\
\hline & & & & $\mathrm{N} 3=48$ & 17.0468 & 0.5520 & 16.440 & 0.190 \\
\hline & & \multirow{3}{*}{ Height } & \multirow{3}{*}{$\mathrm{Cm}$} & $\mathrm{N} 1=24$ & 171.563 & 1.032 & 172.00 & 0.208 \\
\hline & & & & $\mathrm{N} 2=24$ & 171.231 & 1.414 & 171.00 & -0.370 \\
\hline & & & & $\mathrm{N} 3=48$ & 171.415 & 1.126 & 174.01 & 0.096 \\
\hline & & \multirow{3}{*}{ Weight } & \multirow{3}{*}{$\mathrm{Kg}$} & $\mathrm{N} 1=24$ & 64.614 & 1.6297 & 65.000 & 0.329 \\
\hline & & & & $\mathrm{N} 2=24$ & 64.123 & 1.6895 & 64.500 & 0.662 \\
\hline & & & & $\mathrm{N} 3=48$ & 62.893 & 1.5672 & 65.00 & 0.251 \\
\hline \multirow{3}{*}{2} & \multirow{3}{*}{\multicolumn{2}{|c|}{ Experience }} & \multirow{3}{*}{ Year } & $\mathrm{N} 1=24$ & 6.092 & 6.092 & 0.3731 & 5.800 \\
\hline & & & & $\mathrm{N} 2=24$ & 6.1079 & 6.1079 & 0.3560 & 6.100 \\
\hline & & & & $\mathrm{N} 3=48$ & 6.121 & 6.121 & 0.3737 & 5.899 \\
\hline
\end{tabular}

Table (4) indicated that squewness values ranged from 0.921 to 0.370 and this indicates homogeneity of the three groups and data normality.
To assure that there are no differences in basic variables among the three groups, the researchers performed OneWay ANOVA as seen in table (5)

Table (5)

One-Way ANOVA for comparison of the three groups

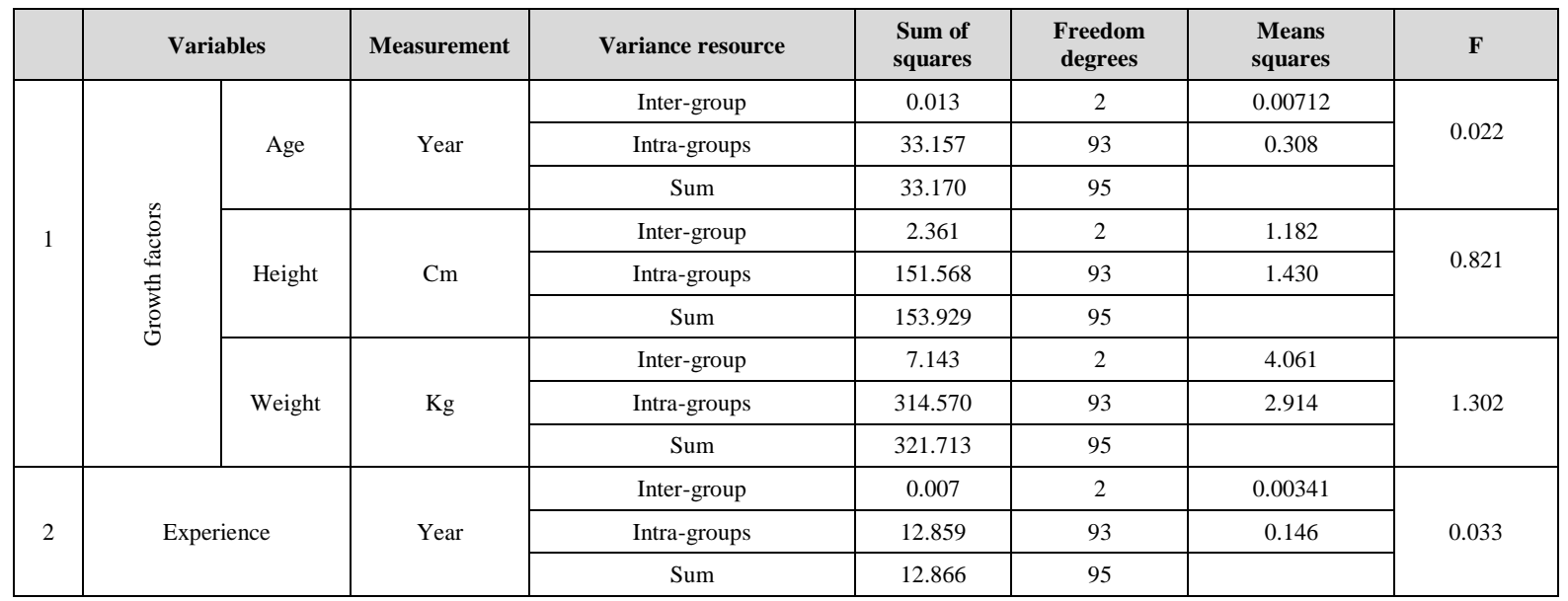

F table value on $\mathbf{P} \leq \mathbf{0 . 0 5}=\mathbf{3 . 5 5}$

Table (5) indicated that there are no statistically significant differences among the three groups on basic variables.

\section{Procedures for designing tests:}
A) Designing Tests
B) Identification of Tests
C) Trying Final Versions of Tests
D) Procedures for Measurement and Running the Ball Canon According to Each Test
E) Validating Tests
F) Deriving Standards

A) Designing Tests: The researchers designed (10) tests for measuring performance endurance of some basic skills for junior table tennis players less than (18) years using a ball canon (TIBHAR - ROBO Pro Master). The researchers considered the following:

- Tests should be consistent with this research aims

- Tests should cover the whole area of the table surface

- Players should perform with forehand, backhand or both faces

- Performance situation should be similar to real competitive situations

- Tests should be exciting to stimulate players' motivation

- Tests are designed for right-handed players. Therefore, ball trajectory should be modified for lift-handed players. 
The researchers established a preliminary version of these tests and presented them to (8) experts of table tennis (4 of them were faculty members and 4 were experienced coaches). Experts expressed their opinions to accept, modify or eliminate tests.

B) Identification of Tests: The researchers reviewed the available studies related to this research (Suchomel, Ales 2010: 75) (Pushpendra Purashwani et al 2010: 89) ( Saleh, Sherif F. 2011: 116) (Lefta, Murtada A. 2012: 10) (Sharma, R. 2013: 84-88) (Katsikadelis, M. et al 2014) (Li, Tao 2015) (Letts, Greg 2016).

The researcher benefited from these studies in designing the recommended tests for evaluating the performance endurance level of basic tables tennis skills that are frequently used in real competitions. They also used the double-head ball canon for programming each test instantly through the easy-to-use control unit. The researchers modified the tests according to experts' opinions.

\section{C) Trying Final Versions of Tests: The researchers} followed the following procedures:

1- Interviews with coaches of junior teams less than 18 years for getting their agreement on application

\section{2- Preparing a data recording form for each player}

3- Preparing the tools required:

- TBHAR (ROBO Pro Master) double-head ball canon

- Hundred (100) certified table tennis balls (ITTF approved)
- One certified table (ITTF approved)

- One certified net (ITTF approved)

- One table tennis racquet (Each player is required to bring his/her own racquet to the test)

\section{Pilot study:}

Pilot study was performed on a randomly chosen (16) players from the same research community and outside the fain sample to: Verify the validity of the ball canon Verify the suitability of ball variables (velocity - spin place - direction - progression) on the table surface to the age group - Verify the applicability of tests after experts' modifications - Verify conditions and criteria of tests Identification of each test's duration - Identification of between-tests rest intervals - Identification of total duration of test battery - Identification of the suitable number of daily tested players - Assuring tests progression from easy to difficult - Assuring the suitability of data recording form.

\section{D) Procedures for Measurement and Running the Ball Canon According to Each Test:}

1- The ball canon is fixed to the middle of table surface facing the player and $30 \mathrm{~cm}$ away from the table

2- The player stands $50 \mathrm{~cm}$ away from the middle of table holding the racquet and ready for the test

3- The ball canon is calibrated according to each test's objective as seen in the following tables:

Test (1): Straight forehand stroke

\begin{tabular}{|c|c|c|c|c|}
\hline & Head 1 & Head 2 & Head 1 & Head 2 \\
\hline Ball & 1 & 2 & 5 & 4 \\
\hline Velocity & 5 & 6 & 2 & 3 \\
\hline Spin & 2 & 3 & 4 & 1 \\
\hline Place & 10 & 7 & 60balls / min \\
\hline Ball/min & \multicolumn{2}{|c|}{ Performance for 2 min } \\
\hline Duration & \multicolumn{5}{|c|}{} \\
\hline
\end{tabular}

The previous table undicates that the device has two heads for ball throwing. Each head can control ball speed, type of spine, place of contact with the table and sequence of balls during the time identified by the coach.

\section{Recording:}

- The coach records the number of balls hit from different places on the table to reach the other side

- Balls that do not touch the table surface of the other side are not recorded

\section{Statistical treatment:}

The researchers calculated the following: mean - SD median - squewness - Person's correlation coefficient Cronbach's Alpha - One-Way ANOVA - benchmarks

\section{E) Validating Tests:}

For verifying easiness and difficulty levels of tests the researchers applied the (10) tests to group $1(n=24)$ to identify any difficulties that may arise during main application. 
Table (6)

Mean, SD, Median and Squewness for group 1 on the recommended tests $(n=24)$

\begin{tabular}{|c|c|c|c|c|c|}
\hline & Tests & Mean & SD & Median & Squewness \\
\hline 1 & Straight forehand stroke & 56.25 & 0.737 & 56.0 & 0.444 \\
\hline 2 & Straight forehand/backhand stroke & 60.16 & 0.816 & 60.00 & 0.716 \\
\hline 3 & Spiral forehand stroke & 44.65 & 0.494 & 45.00 & 0.551 \\
\hline 4 & Spiral forehand/backhand stroke & 53.54 & 0.508 & 54.00 & 0.179 \\
\hline 5 & Smash forehand stroke & 57.00 & 0.780 & 58.00 & 1.119 \\
\hline 6 & Forehand/backhand block and suppression & 47.29 & 0.806 & 47.00 & 0.604 \\
\hline 7 & Balloon backhand defense and spiral forehand stroke & 60.54 & 1.382 & 60.50 & 1.225 \\
\hline 8 & Forehand/backhand various attack strokes & 51.45 & 0.779 & 52.00 & 1.065 \\
\hline 9 & Forehand/backhand various defense strokes & 50.250 & 1.073 & 50.00 & 0.086 \\
\hline 10 & Forehand/backhand various attack and defense strokes & 71.20 & 0.832 & 71.00 & 0.426 \\
\hline
\end{tabular}

Table (6) indicated that squewness values ranged from

0.086 to $1.224-5$. This indicates normality of data as it is free of radical distributions.

\section{Validity of Tests:}

The researchers calculated distinct validity through identifying the upper and lower quartiles for each player in addition to internal consistency in distinguishing high and low levels. For this purpose, the researchers applied the tests to group 3 from 7-9-2016 to 10-9-2016.

Table (7)

Distinct validity of the recommended tests $(n=48)$

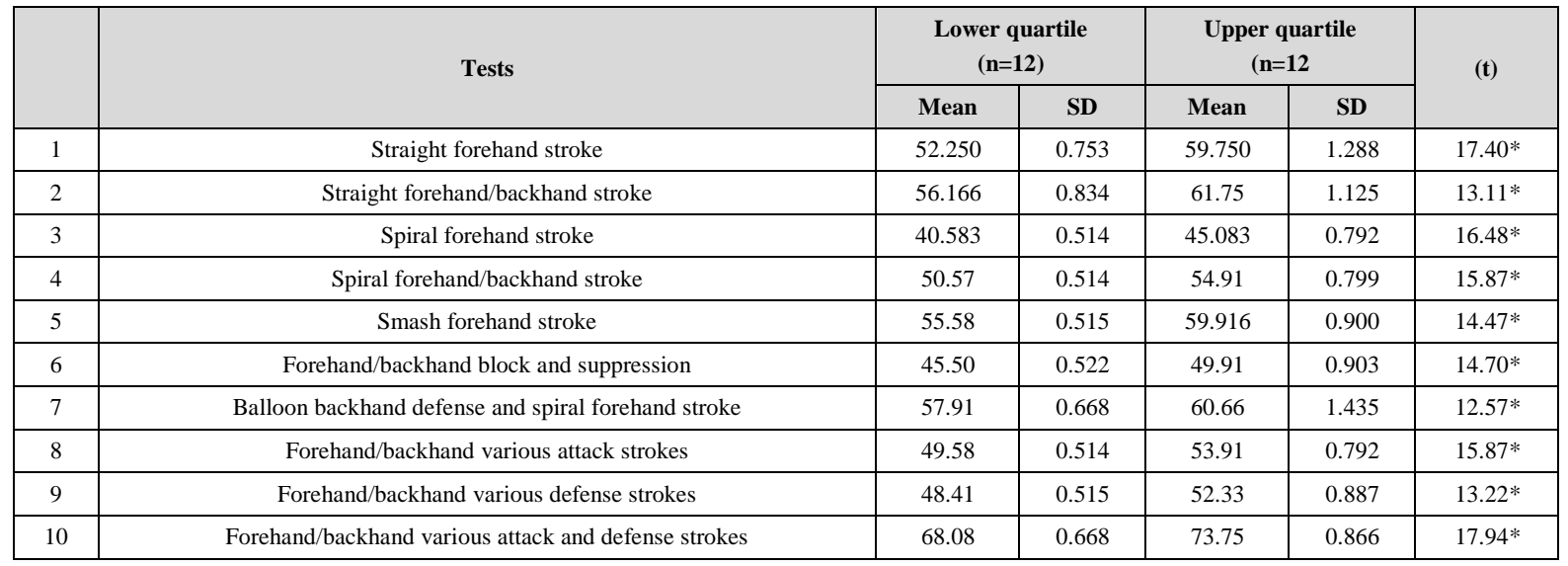

(t) table value on $\mathbf{P} \leq \mathbf{0 . 0 5}=\mathbf{2 . 0 7}$

Table (7) indicated statistically significant differences between the high and low groups on results of the recommended tests. This indicates the validity of tests as they distinguished between the two groups.

\section{Reliability of Tests:}

To calculate reliability of tests, the researchers used the test/retest procedure on group $2(n=24)$ from 17-9-2016 to 21-9-2016 as tested the group and retest them with 3-day interval between test and retest to calculate Cronbach's Alpha.

Table (8)

Reliability of recommended tests $(n=24)$

\begin{tabular}{|c|c|c|c|c|c|c|c|}
\hline & \multirow{2}{*}{ Variables } & \multicolumn{2}{|c|}{ Test } & \multicolumn{2}{|c|}{ Retest } & \multirow{2}{*}{$\mathbf{R}$} & \multirow{2}{*}{ Alpha } \\
\hline & & Mean & SD & Mean & SD & & \\
\hline 1 & Straight forehand stroke & 59.750 & 1.288 & 60.08 & 0.996 & 0.939 & 0.952 \\
\hline
\end{tabular}




\begin{tabular}{|c|l|l|l|l|l|l|l|}
\hline 2 & Straight forehand/backhand stroke & 61.75 & 1.125 & 62.00 & 1.044 & 0.859 & 0.903 \\
\hline 3 & Spiral forehand stroke & 45.083 & 0.792 & 45.58 & 0.792 & 0.783 & 0.842 \\
\hline 4 & Spiral forehand/backhand stroke & 54.91 & 0.799 & 55.75 & 0.965 & 0.920 & 0.994 \\
\hline 5 & Smash forehand stroke & 59.916 & 0.900 & 60.08 & 0.996 & 0.921 & 0.911 \\
\hline 6 & Forehand/backhand block and suppression & 49.91 & 0.903 & 50.03 & 0.778 & 0.827 & 0.903 \\
\hline 7 & Balloon backhand defense and spiral forehand stroke & 6.66 & 1.435 & 64.41 & 1.50 & 0.954 & 0.913 \\
\hline 8 & Forehand/backhand various attack strokes & 53.91 & 0.792 & 53.58 & 1.223 & 0.863 & 0.905 \\
\hline 9 & Forehand/backhand various defense strokes & 52.33 & 0.887 & 52.66 & 0.984 & 0.867 & 0.803 \\
\hline 10 & Forehand/backhand various attack and defense strokes & 73.75 & 0.668 & 74.16 & 0.834 & 0.817 & 0.854 \\
\hline
\end{tabular}

\section{$R$ table value on $P \leq \mathbf{0 . 0 5}=\mathbf{0 . 7 0 7}$}

Table (8) indicated high test/retest correlation for all tests. Total Cronbach's Alpha coefficient for the whole set of tests was 0.971 indicating high reliability of tests.

F) Deriving Standards:
After verifying validity and reliability of tests, the researchers applied the (10) tests for all participants $(\mathrm{n}=96)$ from 5-10-2016 to 10-10-2016 during the Open Republic Championship (RAS ELBAR 2016). Accordingly, the researchers prepared standard levels tables and benchmarks tables.

Table (9)

Standard Levels of Performance Endurance Tests (n=96)

\begin{tabular}{|c|c|c|c|c|c|c|c|c|c|c|c|c|c|c|c|c|c|c|c|}
\hline \multicolumn{2}{|c|}{$\begin{array}{l}\text { (1) straight } \\
\text { forehand } \\
\text { stroke }\end{array}$} & \multicolumn{2}{|c|}{$\begin{array}{l}\text { (2) straight } \\
\text { forehand/backh } \\
\text { and strokes }\end{array}$} & \multicolumn{2}{|c|}{$\begin{array}{l}\text { (3) spiral } \\
\text { forehand } \\
\text { stroke }\end{array}$} & \multicolumn{2}{|c|}{$\begin{array}{l}\text { (4) spiral } \\
\text { forehand } \\
\text { /backhand } \\
\text { strokes }\end{array}$} & \multicolumn{2}{|c|}{$\begin{array}{l}\text { (5) Smash } \\
\text { forehand } \\
\text { stroke }\end{array}$} & \multicolumn{2}{|c|}{$\begin{array}{c}(6) \\
\text { forehand/bac } \\
\text { khand block } \\
\text { and } \\
\text { suppression }\end{array}$} & \multicolumn{2}{|c|}{$\begin{array}{l}\text { (7) backhand } \\
\text { balloon } \\
\text { defense and } \\
\text { spiral } \\
\text { forehand } \\
\text { stroke }\end{array}$} & \multicolumn{2}{|c|}{$\begin{array}{l}\text { (8) various } \\
\text { forehand/back } \\
\text { hand attack } \\
\text { strokes }\end{array}$} & \multicolumn{2}{|c|}{$\begin{array}{l}\text { (9) various } \\
\text { forehand/back } \\
\text { hand defense } \\
\text { strokes }\end{array}$} & \multicolumn{2}{|c|}{$\begin{array}{c}\text { (10) various } \\
\text { forehand/back } \\
\text { hand attack } \\
\text { and defense } \\
\text { strokes }\end{array}$} \\
\hline$\stackrel{\Xi}{\simeq}$ & 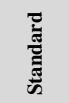 & $\underset{\simeq}{\simeq}$ & 总 & $\underset{\approx}{\approx}$ & 䒿 & 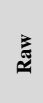 & 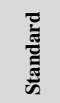 & 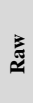 & 䒿 & $\stackrel{\Xi}{\check{\Xi}}$ & 䒿 & $\underset{\Xi}{\approx}$ & 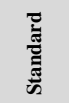 & 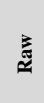 & 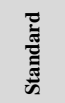 & $\underset{\approx}{\Xi}$ & 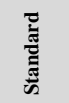 & $\underset{\cong}{\approx}$ & 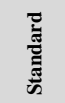 \\
\hline 35 & -1.755 & 49 & -1.120 & 30 & -1.33 & 26 & -1.628 & 32 & -1.318 & 45 & -1.292 & 28 & -1.856 & 31 & -1.755 & 37 & -1.370 & 42 & -1.795 \\
\hline 38 & -1.601 & 52 & -0.964 & 32 & -1.24 & 28 & -1.542 & 35 & -1.164 & 48 & -1.184 & 35 & -1.603 & 35 & -1.563 & 39 & -1.300 & 45 & -1.673 \\
\hline 40 & -1.498 & 55 & -.0809 & 35 & -1.109 & 30 & -1.369 & 37 & -1.061 & 52 & -1.014 & 38 & -1.490 & 38 & -1.418 & 42 & -1.196 & 50 & -10.471 \\
\hline 42 & -1.395 & 57 & -0.705 & 37 & -1.021 & 32 & -1.354 & 39 & $\begin{array}{l}-0.958 \\
\end{array}$ & 55 & -0.934 & 42 & -1.350 & 42 & -1.226 & 45 & -1.092 & 59 & -1.106 \\
\hline 45 & -1.240 & 59 & -0.601 & 41 & -0.844 & 35 & -1.239 & 42 & $\begin{array}{l}-0.803 \\
\end{array}$ & 60 & -0.756 & 45 & -1.242 & 48 & -0.937 & 55 & -1.057 & 65 & -0.863 \\
\hline 48 & -1.086 & 60 & -0.549 & 45 & $0 .-667$ & 37 & -1.153 & 50 & -0.391 & 62 & -0.684 & 49 & -1.098 & 52 & -0.745 & 60 & -0.571 & 70 & -0.660 \\
\hline 52 & -0.880 & 65 & -0.185 & 47 & +0.579 & 40 & -1.109 & 52 & -0.288 & 65 & -.577 & 55 & -0.882 & 55 & -0.600 & 68 & -0.294 & 75 & -0.457 \\
\hline 55 & -0.725 & 67 & -0.793 & 52 & -0.357 & 45 & 0.807 & 55 & $\begin{array}{l}-0.134 \\
\end{array}$ & 70 & -0.398 & 60 & -0.702 & 59 & -0.408 & 75 & -0.50 & 78 & -0.341 \\
\hline 59 & -0.519 & 70 & 0.029 & 58 & -0.0926 & 48 & $\begin{array}{l}-0.677 \\
\end{array}$ & 59 & 0.719 & 75 & -0.220 & 65 & -0.522 & 65 & -0.119 & 79 & 0.087 & 80 & -0.255 \\
\hline 65 & -0.210 & 75 & 0.229 & 60 & -0.0041 & 55 & -0.374 & 62 & 0.226 & 79 & -0.077 & 70 & -0.311 & 69 & 0.0732 & 85 & 0.296 & 85 & -0.142 \\
\hline 68 & -0.055 & 79 & 0.437 & 65 & 0.217 & 58 & -0.245 & 65 & 0.380 & 85 & 0.137 & 72 & -0.269 & 72 & 0.0521 & 90 & 0.469 & 88 & 0.069 \\
\hline 70 & 0.047 & 85 & 0.749 & 68 & 0.349 & 62 & -0.072 & 68 & 0.535 & 86 & 0.173 & 75 & -0.161 & 75 & 0.361 & 95 & 0.643 & 92 & 0.231 \\
\hline 73 & 0.201 & 90 & 1.009 & 70 & 0.438 & 75 & 0.490 & 72 & 0.741 & 90 & 0.316 & 80 & 0.0187 & 77 & 0.412 & 99 & 0.782 & 95 & 0.352 \\
\hline 75 & 0.304 & 95 & 1.268 & 72 & 0.526 & 80 & 0.706 & 76 & 0.947 & 95 & 0.494 & 89 & 0.199 & 80 & 0.602 & 101 & 0.872 & 100 & 0.556 \\
\hline 79 & 0.5100 & 98 & 1.432 & 75 & 0.659 & 85 & 0.922 & 79 & 1.102 & 99 & 0.637 & 92 & 0.451 & 82 & 0.698 & 105 & 0.990 & 105 & 0.758 \\
\hline 82 & 0.665 & 100 & 1.528 & 79 & 0.836 & 90 & 1.136 & 80 & 1.153 & 102 & 0.744 & 96 & 0.595 & 84 & 0.751 & 112 & 1.233 & 109 & 0.920 \\
\hline 85 & 0.819 & 103 & 1.310 & 82 & 0.968 & 92 & 1.225 & 85 & 1.41 & 105 & 0.852 & 100 & 0.739 & 86 & 0.891 & 119 & 1.47 & 112 & 1.042 \\
\hline 87 & 0.923 & 105 & 1.053 & 86 & 1.145 & 95 & 1.354 & 88 & 1.565 & 111 & 1.066 & 105 & 0.920 & 88 & 0.987 & 120 & 1.511 & 116 & 1.204 \\
\hline 90 & 1.077 & 107 & 1.892 & 89 & 1.278 & 97 & 1.441 & 90 & 1.668 & 116 & 1.245 & 109 & 1.064 & 89 & 1.035 & & & & \\
\hline 92 & 1.180 & 110 & 2.048 & 92 & 1.41 & 99 & 1.527 & 92 & 1.771 & 125 & 1.566 & 115 & 1.280 & 92 & 1.180 & & & & \\
\hline 95 & 1.335 & 112 & 2.152 & 97 & 1.63 & 101 & 1.614 & 93 & 1.823 & 132 & 1.816 & 118 & 1.388 & 95 & 1.324 & & & & \\
\hline
\end{tabular}

Table (10)

Benchmarks and its related degrees for performance endurance tests ( $n=96)$

\begin{tabular}{|c|c|c|c|c|c|c|c|c|c|c|}
\hline $\begin{array}{c}\text { Benchmark } \\
\mathrm{s}\end{array}$ & $\begin{array}{c}\text { (1) } \\
\text { straight } \\
\text { forehand } \\
\text { stroke }\end{array}$ & $\begin{array}{l}\text { (2) straight } \\
\text { forehand/ba } \\
\text { ckhand } \\
\text { strokes }\end{array}$ & $\begin{array}{l}\text { (3) spiral } \\
\text { forehand } \\
\text { stroke }\end{array}$ & $\begin{array}{l}\text { (4) spiral } \\
\text { forehand/ba } \\
\text { ckhand } \\
\text { strokes }\end{array}$ & $\begin{array}{l}\text { (5) Smash } \\
\text { forehand } \\
\text { stroke }\end{array}$ & $\begin{array}{c}\text { (6) } \\
\text { forehand } \\
\text { /backhand } \\
\text { block and }\end{array}$ & $\begin{array}{c}\text { (7) } \\
\text { backhand } \\
\text { balloon } \\
\text { defense and } \\
\text { spiral }\end{array}$ & $\begin{array}{c}\text { (8) various } \\
\text { forehand } \\
\text { /backhand } \\
\text { attack }\end{array}$ & $\begin{array}{l}\text { (9) various } \\
\text { forehand } \\
\text { /backhand } \\
\text { defense }\end{array}$ & $\begin{array}{c}\text { (10) } \\
\text { various } \\
\text { forehand } \\
\text { /backhan } \\
\text { d attack }\end{array}$ \\
\hline
\end{tabular}




\begin{tabular}{|c|c|c|c|c|c|c|c|c|c|c|}
\hline & & & & & & suppression & $\begin{array}{l}\text { forehand } \\
\text { stroke }\end{array}$ & strokes & strokes & $\begin{array}{c}\text { and } \\
\text { defense } \\
\text { strokes }\end{array}$ \\
\hline 100 & 95 & 112 & 97 & 101 & 93 & 132 & 118 & 95 & 127 & 116 \\
\hline 95 & 92 & 109 & 93 & 96 & 87 & 125 & 116 & 90 & 121 & 112 \\
\hline 90 & 86 & 104 & 90 & 90 & 81 & 121 & 112 & 85 & 118 & 109 \\
\hline 85 & 83 & 99 & 88 & 85 & 77 & 118 & 106 & 79 & 112 & 104 \\
\hline 80 & 79 & 93 & 85 & 82 & 70 & 115 & 101 & 74 & 109 & 99 \\
\hline 75 & 74 & 91 & 80 & 76 & 68 & 112 & 98 & 71 & 106 & 93 \\
\hline 70 & 71 & 89 & 76 & 73 & 64 & 109 & 95 & 70 & 101 & 88 \\
\hline 65 & 69 & 85 & 74 & 70 & 63 & 105 & 90 & 68 & 98 & 85 \\
\hline 60 & 66 & 83 & 70 & 64 & 61 & 101 & 86 & 64 & 93 & 82 \\
\hline 55 & 63 & 80 & 67 & 59 & 58 & 98 & 84 & 61 & 88 & 78 \\
\hline 50 & 59 & 77 & 63 & 55 & 55 & 95 & 80 & 57 & 84 & 77 \\
\hline 45 & 58 & 76 & 59 & 52 & 53 & 91 & 79 & 55 & 82 & 72 \\
\hline 40 & 56 & 75 & 52 & 49 & 49 & 86 & 74 & 53 & 78 & 68 \\
\hline 35 & 54 & 69 & 48 & 46 & 46 & 81 & 67 & 48 & 74 & 62 \\
\hline 30 & 51 & 65 & 45 & 43 & 42 & 78 & 55 & 45 & 67 & 59 \\
\hline 25 & 45 & 63 & 43 & 40 & 39 & 75 & 47 & 40 & 62 & 55 \\
\hline 20 & 53 & 60 & 39 & 36 & 37 & 63 & 41 & 37 & 59 & 51 \\
\hline 15 & 39 & 55 & 35 & 32 & 36 & 59 & 38 & 34 & 52 & 49 \\
\hline 10 & 38 & 52 & 33 & 29 & 34 & 51 & 35 & 33 & 45 & 45 \\
\hline 5 & 35 & 49 & 30 & 26 & 32 & 45 & 28 & 31 & 37 & 42 \\
\hline
\end{tabular}

Table (10) showed benchmarks and its related degrees for performance endurance tests of basic skills for junior table tennis players using the ball canon. Through these benchmarks junior players can be categorized according to their raw scores and benchmarks from very weak to excellent. The researchers think that this can be as follows: less than $5 \%$ to $25 \%=$ very weak $-26 \%$ to $45 \%=$ weak $46 \%$ to $60 \%=$ acceptable $-61 \%$ to $79 \%=\operatorname{good}-80 \%$ and higher $=$ excellent. This indicates the importance of these standard levels and benchmarks for coaches of this age group as it enables them to categorize their players objectively and design their training plans accordingly.

The researchers thinks thatr these tests are clear and valid indicators for improoving the physical aspects in general and especially performance endurance and its effects on the technical performance of the table tennis player during this critical age stage. This particular stage represents the transformation from junior stage to strong and violent competitions of the youth and men championships.

Heaton, J. (2012) indicated that performance endurance is a major physical component required by table tennis players to improve their physical and functional effeciency. It has positiive effects on several variables that control the improvement of technical performance. It also affects steady focus and readiness for struggle from the beginning to the end of the match as it includes ball rally with speeds exceeding 50m/sec (Heaton, J. 2012: 72).
Schlager, W. \& Berned, G. (2011) indicated that performance endurance is a major variable trhat affects the player's long-term physical and mental resistance that may reach the limits of major fatigue. This fatigue may lead the player to lose the match, which in turn affects his/her rank or being denied a world champion title along with his/her country (Schlager, W. \& Berned, G. 2011: 154).

The researchers think that controling the endurance level of table tennis players have significant effects on match results as seen in several world championship finals recently. In some cases, players managed to win the match by its end although the opponent advanced by some runs. This is because the winner enjoyed higher levels of performance endurance under physical and mental pressure. This competitive performance endurance enables players to reach draw and even win the match as it helps such players to deal with the ball speed, timing, location and spine type for his/her own benefit.

\section{Conclusions:}

According to this research aims, methods and statistical treatments, the researchers concluded the following:

1- The set of tests enjoy high validity and reliability and this indicates it objectivity

2- The set of tests diagnose weaknesses and strengths of junior table tennis players less than 18 years concerning 
performance endurance of some basic skills on various places of the table

3- The set of tests cover the most frequently used basic skills in various game situations

4- Criteria of tests (velocity - spin - direction - place) can be used in measuring all individual and complex basic skills according to various game situations

5- The set of tests help categorizing players and improving their abilities according to fast improvements in table tennis

6- The researchers established the standard levels of performance endurance tests for junior table tennis players less than 18 years

7- The researchers established the benchmarks of performance endurance tests for junior table tennis players less than 18 years

8- The researchers established the levels of performance endurance for junior table tennis players less than 18 years using these tests

\section{Recommendations:}

According to these conclusions, the researchers recommend the following:

1- Using performance endurance tests of some basic skills for junior table tennis players in training and selecting junior players

2- Using performance endurance tests of some basic skills for junior table tennis players as a means for evaluating players and as a means for training endurance in table tennis

3- Considering the results of this research when designing training programs for junior table tennis players less than 18 years

4- These tests are indicators for technical performance. Therefore, it is important to use them in evaluating players through follow-up measurements.

5- It is important to improve the physical level of table tennis players less than (18) years in general, and especially the performance endurance componenet, because of its positive effects on the technical performance levels during matches.

References:
1- Abd El-Fattah, Abu Al-Ela A. (2012): Contemporary Sports Training. Dar Al-Fikr Al-Araby - Cairo - Egypt (in Arabic)

2- Abd El-Gawad, Mohamed E. (2014): A training program for improving footwork and its effects on performing some attack tactics for junior table tennis players. PhD thesis, Faculty of Physical Education - Tanta University (in Arabic)

3- Abd El-Zaher, Mohamed M. (2014): Physiological bases for planning training loads. Markaz Al-Ketab Press, Cairo - Egypt (in Arabic)

4- Ales Suchomel (2010) A Comparison of Exercise Intensity on Different Player Levels in Table Tennis, International Journal of Table Tennis Sciences, 11th ITTF Sports Science Congress, Yokohama, Japan, (75).

5- Farahat, Laila E. (2012): Measurment and testing in physical education, 2nd ED. Markaz Al-Ketab Press, Cairo - Egypt (in Arabic)

6- Francisco Pradas, Pablo Floría, Luís Carrasco, Alfonso Beamonte (2010)Design and Development of an Observational Tool for Evaluating Table Tennis Singles Matches, International Journal of Table Tennis Sciences, No 6, International Table Tennis Federation, Switzerland, (177).

7- Ghareeb, Mohamed S. (2013): Advanced international studies for preparing table tennis coaches - level 2. Cairo - Egypt (in Arabic)

8- Greg Letts (2016)Footwork Drills - Training by Yourself in Table Tennis/Ping-Pong, http://tabletennis.about.com/od/ tabletennisrobots/fr/robopong.htm .

9- Jenny Heaton (2012) Table Tennis Skills - Techniques - Tactics, Crowood Ramsburg(72)

10- Jun-ichi Kasai, Ohta Akira, Jung Tae Eung, Takeshi Mori4 (2010) Research on table tennis player's cardiorespiratory endurance, International Journal of Table Tennis Sciences, No 6, International Table Tennis Federation, Switzerland, (14).

11- Lefta, Murtada A. (2012): Effects of a training program for improving cross-legs step on the accuracy of some forehand strokes of junior table tennis players in Sweden. Master thesis, Faculty of Physical Education Zagazig University (in Arabic)

12- Michail Katsikadelis, Pilianidis Theophilos, Nikolaos Mantzouranis (2014) Test-retest reliability of the "table tennis specific battery test" in competitive level young 
players, European Psychomotricity Journal 6, https://www.researchgate. net/publication /281121298_

13- Michail Katsikadelis, Pilianidis Theophilos, Nikolaos Mantzouranis, (2014) Heart rate variability of young Table Tennis players with the use of the Multiball training, Biology of Exercise, https://www.biologyofexercise.com/images/issues/1023.p df

14- Michail Katsikadelis, Theofilos Pilianidis, Alexandra Misichroni (2010) Comparison of Rally Time in XXIX Beijing (2008) and XXVIII Athens (2004)Olympic Table Tennis Tournaments, International Journal of Table Tennis Sciences, No 6, International Table Tennis Federation, Switzerland, (51).

15- Miran Kondrič, Alessandro Moura Zagatto, Damir Sekulić (2013) The Physiological Demands of Table Tennis: A Review, Journal of Sports Science and Medicine 12, http://www.jssm.org/ abstreviewajssm-12362.xml.xml , (362).

16- Pushpendra Purashwani, A.K. Datta, Manoj Purashwani (2010) Construction of Norms for Skill Test Table Tennis Players, International Journal of Table
6, Tennis Sciences, No 6, International Table Tennis Federation, Switzerland, (89).

17- Rajeev Sharma (2013) Great Table Tennis Practice Drills for Improved Footwork, https://www.killerspin.com/blog/practice-drills-forimproved-footwork.

18- Sherif Fathy Saleh (2011) Designing and Calibrating Specific Tests for Counter-Attack Skills in junior table tennis Players using Modified Electronic ( Ball Canon (Table Tennis Robot), Theories \& Applications, the International Edition(TIAE), Faculty of Physical Education ,Abu Qir - Alexandria University, (110-123).

19- Tao Li (2015) Forehand Loop Mastery, Discover how to quickly and easily unleash lethal attacks and crush your competition with deadly forehand loops, http://tabletennisuniversity.com/p/forehand-loop-mastery.

20- The International Table Tennis Federation (2016)Handbook International Table Tennis Federation Switzerland.(29)

21- Werner Schlagers, Bernd - Ulrich Gross (2011) Table Tennis Tips From A World Champion, Meyer \& Meyer Sport, England(154) 